\title{
A Web-Based Interface for Student Peer Review, Problem-Based Learning, and Peer Pressure
}

\author{
Joshua M. Duke*
}

\begin{abstract}
Because many students in land-grant colleges focus their studies in the natural sciences, they often find the writing assignments associated with classes in the social science of natural resource management to be especially challenging. Such writing assignments tend to depend on argumentation rather than finding the answer or controlled experimentation. This paper describes developing and implementing a web-based interface for a course in environmental law to overcome some of these difficulties. In a problem-based learning context, the interface promotes student peer review, which improves argumentation. Data suggest that students are comfortable learning in groups and that learning becomes easier when coupled with group activities, including peer review through the interface. In addition, the quality of student argumentation is found to improve through peer pressure.
\end{abstract}

$\mathrm{T}$ HIS paper discusses results on student learning from a revision of the course, Topics in Environmental Law. The revision emphasized problem-based learning (PBL) via some common techniques and a unique technological interface, which allows for student peer review on the web. Starting with a simple guestbook program available from the University of Delaware for its Unix environment, the instructor conceptualized and designed a web-based interface that allows students to peer review group members' research and analyses. The main objective of this paper is to investigate how student learning is affected when PBL objectives are sought. Data are presented and assessed from student evaluations, which were administered to two classes before the PBL treatment and two classes after the treatment. The principal conclusions from an examination of these data are that learning seems to have become easier for the students after the treatment, while other areas of evaluation are not negatively affected by PBL. Moreover, low- and midperforming students seem to produce higher-quality work. This effect is due as much to the force of peer pressure as to the benefits of peer review. A second data set, consisting of subjective student evaluations, is examined to evaluate student perceptions about the in-class PBL experience.

In the second section of this paper, the pre-treatment version of the course is described-i.e., as it was taught before PBL and student peer review became the centerpiece of the learning experience. The third section discusses the posttreatment course in which PBL is used to achieve learning goals. The fourth section then describes the web-based inter-

Department of Food and Resource Economics, Townsend Hall 205, Univ. of Delaware, Newark, DE 19716. Received 29 Aug. 2002. * Corresponding author(duke@UDel.edu).

Published in J. Nat. Resour. Life Sci. Educ. 32:52-56 (2003). http://www.JNRLSE.org

(C) American Society of Agronomy

677 S. Segoe Rd., Madison, WI 53711 USA face, focusing on the way it enables and complements PBL and student peer review methods. Data from student evaluations are discussed and assessed in the fifth section, including the learning outcomes of the interface and with special attention to the PBL and student peer review methods. The sixth section offers subjective evaluations from the instructor and a concluding discussion of the effect of the treatment on student learning.

\section{A SUMMARY OF THE COURSE: PRE-TREATMENT}

Topics in Environmental Law is an undergraduate seminar that has been taught five times in the past $4 \mathrm{yr}$, including one offering in English at the Slovak Agricultural University in Nitra, Slovakia. Among the domestic offerings, the students' majors suggest the great diversity of their experiences, preparation, and interests. The course was designed for students in the College of Agriculture and Natural Resources with majors focusing on environmental economics, policy, or management and nonmajors from the natural sciences. The course also satisfies requirements in environmental science and the legal studies minor.

Perhaps as much as in any subdiscipline, students have already thought deeply about environmental issues and often bring a great deal of predisposition to the classroom along with the desire to learn. Some course objectives emphasize content, centering on learning the institutions and processes of environmental conflict resolution in the USA. Nevertheless, the store of student energy for learning about environmental issues is not always matched by a depth of analytical skills for assessing the performance of institutions that affect the environment.

A second set of course objectives seeks to improve the analytical skills of the students, mainly by teaching a technique developed by legal scholars termed comparative institutional analysis. Comparative institutional analysis is a systematic approach that involves problem definition, data collection, and analysis. Students apply this technique through their own semester-long problem, which focuses on argumentation and the incorporation of peer and instructor reviews. In the first three offerings of this course, including the one in Slovakia, groups and the web-based interface were not used, though some inclass PBL activities were conducted. Then, as now, the students were asked to complete a semester-long analytical problem, though the problem was referred to as a 25-page research paper for the pre-treatment students.

\section{A SUMMARY OF THE COURSE: POST-TREATMENT}

After three semesters of perceiving student resistance to the quantity of work, the paper was recast as a true problem by emphasizing active-learning components and by employing technology. Duch and Allen (1996) argue that well-conceived 
problems can promote higher-order thinking skills. The webbased interface offers novel communication possibilities and the opportunity to improve student work, in part, by peer review, but mainly by increasing the visibility of student work to their peers. Peer pressure is relied on more than peer review to improve effort and the quality of student work.

Each semester, before the first day of class, the 15 to 20 students are assigned into five permanent groups, which emphasize the diversity of majors. Groups are critical because they provide a vehicle for connecting and "mutually reinforc(ing) individual work" (Michaelsen, 1997-1998, p. 1). The syllabus acts as an extensive course contract, specifying high expectations about student performance and effort. The syllabus is also used to communicate the role of the group activities, the web-based interface, student peer review, daily PBL exercises, and the semester-long problem. Environmental law issues have been adapted to the PBL activities, which are assessed in the literature (Rhem, 1998; Albanese and Mitchell, 1993). Although this paper focuses on the webbased interface, student peer review, and the semester-long problem, there are a substantial number of other group activities that quickly familiarize the students with active learning and lead to cohort effects. Almost every class meeting involves active-learning exercises, such as 50-min problems, role-playing advocacy, group reflection, and peer review. At the end of the semester, each group develops and presents a final, synthetic presentation in which they draw lessons across their individual semester-long problems.

\section{THE APPLICATION}

The web-based interface is designed so students can submit six assignments using a web form over the course of a semester. These assignments, collectively, constitute the semester-long paper. The web-based interface posts the assignments so that they are available to students for peer review. Students are graded on their own assignments and on four reviews of their group members' work, which requires at least three substantive comments for each peer review. The web-based interface allows student peer review activities to be completed,

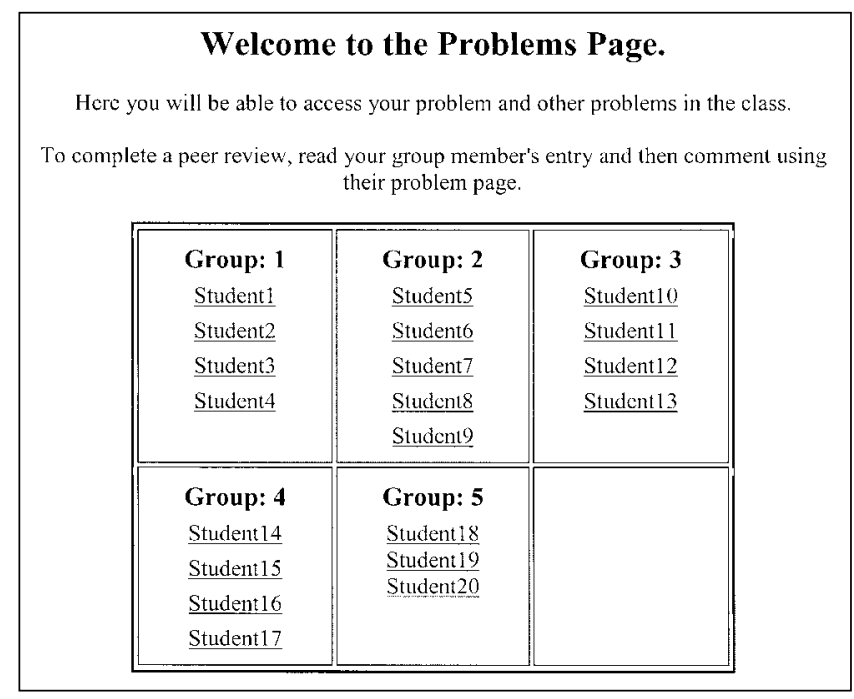

Fig. 1. Problems page. submitted, and reviewed outside of class, which moves learning outside of the classroom and increases the efficiency of class time. In total, each student posts six assignments and receives four posted critiques from each group member. The instructor grades and comments on each assignment. At the end of the semester a revision of the problem is due, which requires students to assimilate between 14 and 18 separate documents of peer and instructor feedback. The technological challenges in designing and maintaining a secure, private interface were substantial (Duke and Whisler, 2002; Whisler, 2002).

The figures offer a picture of actual web pages (without personally identifiable student information) used in the webbased interface. These pages were accessible only to enrolled students and the instructor through a password. Figure 1 shows the gateway to the interface, which is called the problems page. Here students are divided into their semester-long groups, with whom they also share a table during class time. By clicking on any student name, they can read or comment on that student's problem. Student names on the problems page link to any student's individual problem page (Fig. 2). In the boxes, any student or the instructor can read submitted work or reviews. Each student's problem has six sections, which are submitted over the course of the semester using the links under the Authors: Submit Information column heading. When students click on those links, they are taken to a modified guestbook form, such as the example in Fig. 3. Figure 3

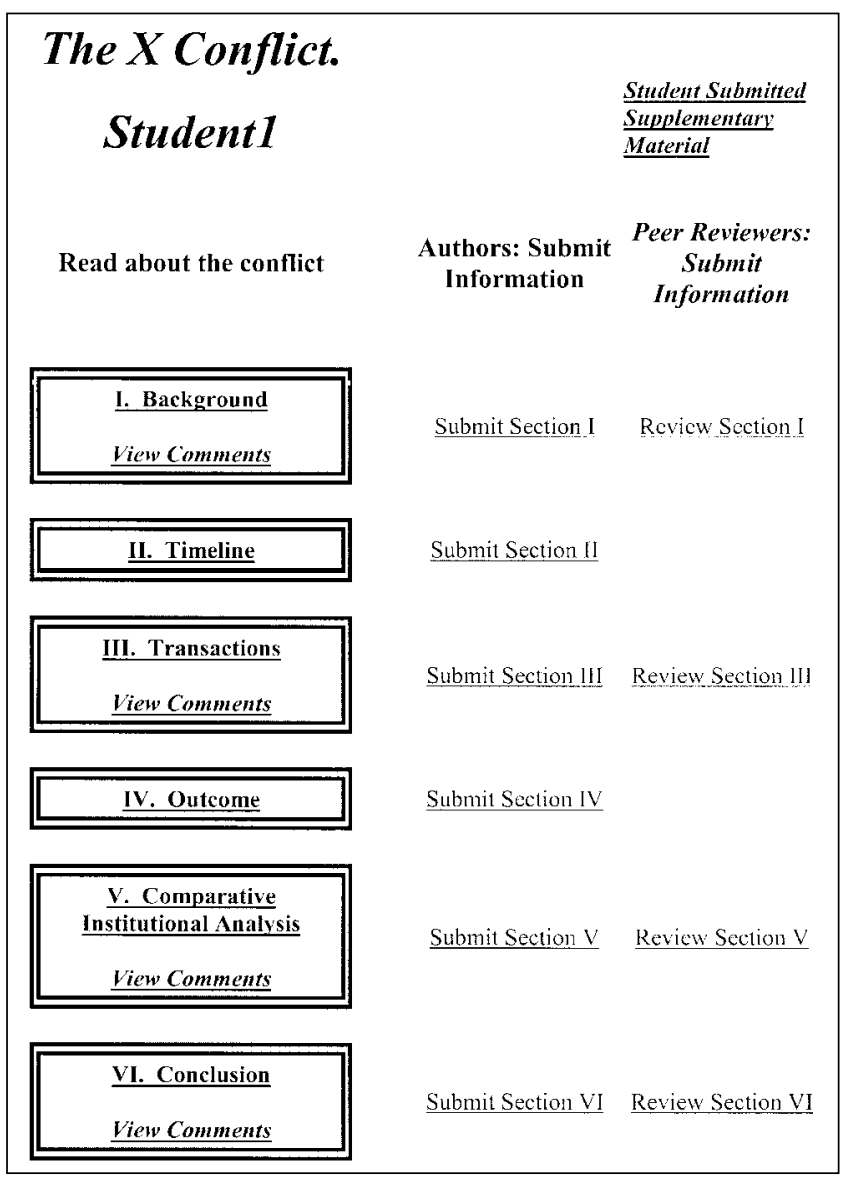

Fig. 2. Student problem page. 
also shows the embedded HTML formatting tags that ensure that all student problems have the same ultimate appearance: fonts, type size, and headings. The peer review forms are similar, and submissions are simply appended as they are posted.

The most recent version of the interface is almost fully automated and requires minimal effort to set up or break down (Duke and Whisler, 2002; Whisler, 2002). Specifically, student names and project titles are saved in one file and another file is executed, which generates the support files and starts a series of automatic at-jobs on the Unix server. Although the instructor's role stops at that point, a quick review of the numbers from the most recent offering suggests the power of the web-based interface. There were 18 students in five groups, each of whom prepared six assignments and four peer reviews on the web, for a total of 180 web forms. A total of 720 files supported the web forms and a perl-script program was run hourly on 180 of these files using the $a t-j o b$. The perl-script program was thus run 4320 times per day, or approximately 470880 times per semester, and each time the instructor received a verification email (which could be screened).

Several learning outputs, though not outcomes, are valuable. The interface provides students with a great deal of feedback. Six assignments are graded with extensive comments. Four of the six assignments are peer reviewed by two or three peers, each of whom makes three substantive comments. Peer reviews are also graded to encourage effort and improve quality. At the end of the semester, each student must revise his or her six assignments into a single comprehensive analysis. This requires the assimilation of 14 to $18 \mathrm{sep}$ arate documents of comments with a minimum of three substantive comments each.

\section{EVALUATIVE DATA ON TREATMENT EFFECTS}

Selection issues and treatment effects plague evaluation of active learning, though evidence of successful techniques exists and was used to design many of the components of this class (Johnson et al., 1998). This paper presents two forms of evaluation. First, selected questions from student evaluations before and after the treatment are used to suggest the effect of PBL on learning (and on the student's evaluation of instructor performance). Data are also presented from a specially designed survey to test PBL learning in this course, which was administered to students in the treatment group.

\section{Data on Treatment Effects}

The standard student evaluation, which is administered at the end of each semester, offers evidence of changes in students' perceptions and learning. Table 1 presents pre-treatment data on students from 1998 and 1999 who were not exposed to the interface and the high level of PBL. Data are also reported on students from 2000 and 2001 who were exposed to the treatment. Importantly, both the pre-treatment and posttreatment groups completed substantially similar work, but with different learning experiences.

Table 1 is divided into two sections. The first five questions demonstrate areas where the students showed no consistent (or strong) pattern of difference between pre-treatment and posttreatment groups. The second five questions reflect areas in which the student ratings dropped after the treatment. Each of the ratings in a given course is compared to the mean of the same question from the other three courses to reveal a percentage change. A positive percentage means that students in the given course gave higher ratings relative to the ratings by students in other years.

The results suggest that the PBL treatment did not markedly nor consistently change ratings of the appropriateness of the written assignments or whether attendance was necessary. These questions were consistently rated very highly. Similarly, student perception of instructor organization, command of material, and effectiveness of presentation seem unaffected by the treatment. These results may calm some fears that PBL leads students to believe that the instructor is not in control of the class. Some instructors may also worry that, without consistent lecturing, students may not fully appreciate the depth of the instructor's knowledge. The data do not demonstrate these effects. Students continued to recognize the importance of class time and the instructor's role in controlling and directing the class.

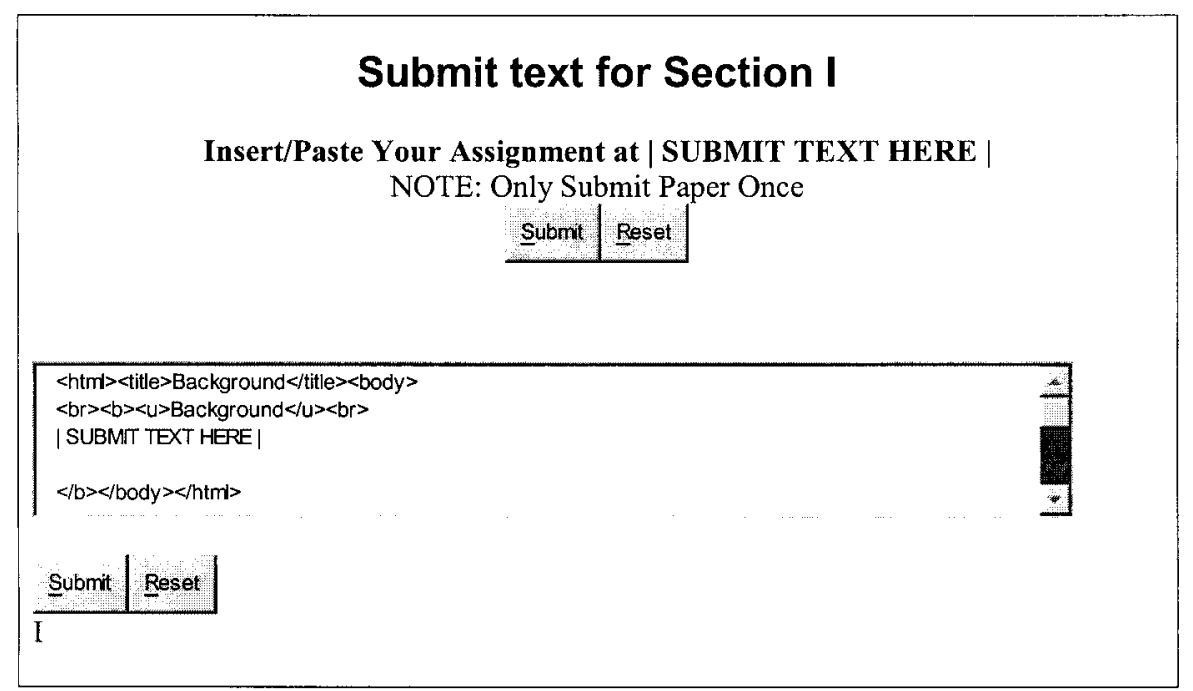

Fig. 3. Sample form for submitting problems.

54 • J. Nat. Resour. Life Sci. Educ., Vol. 32, 2003 
Table 1. Student ratings and deviation from mean before and after problem-based learning (PBL) treatment. The first column under each year is the mean class rating and the second column compares that year's rating to the other 3 years' weighted average rating. The weighted average reflects the number of students in each class. $n=$ number of students.

\begin{tabular}{|c|c|c|c|c|c|c|c|c|c|c|}
\hline \multirow{3}{*}{ Learning treatment } & \multirow[b]{2}{*}{ Scale } & \multicolumn{4}{|c|}{ Pre-treatment } & \multicolumn{4}{|c|}{ Post-treatment } & \multirow[b]{2}{*}{ Weighted avg } \\
\hline & & \multicolumn{2}{|c|}{1998} & \multicolumn{2}{|c|}{1999} & \multicolumn{2}{|c|}{2000} & \multicolumn{2}{|c|}{2001} & \\
\hline & & $n=14$ & & $n=6$ & & $n=12$ & & $n=12$ & & \\
\hline \multicolumn{11}{|l|}{ Questions with no pattern } \\
\hline $\begin{array}{l}\text { Written assignments } \dagger \\
\text { Attendance }+ \\
\text { Instructor's organization } \S \\
\text { Instructor's command đI } \\
\text { Instructor's presentation \# }\end{array}$ & $\begin{array}{l}1-3 \\
1-2 \\
1-5 \\
1-5 \\
1-5\end{array}$ & $\begin{array}{l}1.14 \\
1.07 \\
1.36 \\
1.21 \\
1.36\end{array}$ & $\begin{array}{r}2 \% \\
-7 \% \\
8 \% \\
21 \% \\
20 \%\end{array}$ & $\begin{array}{l}1.33 \\
1.00 \\
1.67 \\
1.50 \\
1.83\end{array}$ & $\begin{array}{r}-18 \% \\
3 \% \\
-19 \% \\
-6 \% \\
-18 \%\end{array}$ & $\begin{array}{l}1.00 \\
1.00 \\
1.17 \\
1.33 \\
1.33\end{array}$ & $\begin{array}{r}18 \% \\
3 \% \\
24 \% \\
9 \% \\
21 \%\end{array}$ & $\begin{array}{l}1.25 \\
1.00 \\
1.70 \\
1.75 \\
2.00\end{array}$ & $\begin{array}{r}-11 \% \\
3 \% \\
-26 \% \\
-33 \% \\
-39 \%\end{array}$ & $\begin{array}{l}1.16 \\
1.02 \\
1.44 \\
1.43 \\
1.59\end{array}$ \\
\hline \multicolumn{11}{|l|}{ Questions dropping after treatment } \\
\hline $\begin{array}{l}\text { Assignments } \dagger \dagger \\
\text { Value of reading assignments }+\$ \\
\text { Willingness to assist } \S \S \\
\text { Work load ITI } \\
\text { Learning \#\# }\end{array}$ & $\begin{array}{l}1-3 \\
1-3 \\
1-5 \\
1-5 \\
1-3\end{array}$ & $\begin{array}{l}1.54 \\
1.14 \\
1.07 \\
2.14 \\
1.00\end{array}$ & $\begin{array}{r}16 \% \\
29 \% \\
39 \% \\
1 \% \\
17 \%\end{array}$ & $\begin{array}{l}1.33 \\
1.67 \\
1.50 \\
1.50 \\
1.33\end{array}$ & $\begin{array}{r}26 \% \\
-17 \% \\
3 \% \\
34 \% \\
-20 \%\end{array}$ & $\begin{array}{l}2.00 \\
1.58 \\
1.58 \\
2.42 \\
1.18\end{array}$ & $\begin{array}{r}-22 \% \\
-13 \% \\
-3 \% \\
-17 \% \\
-5 \%\end{array}$ & $\begin{array}{l}1.92 \\
1.58 \\
2.08 \\
2.25 \\
1.17\end{array}$ & $\begin{array}{r}-15 \% \\
-13 \% \\
-55 \% \\
-6 \% \\
-3 \%\end{array}$ & $\begin{array}{l}1.74 \\
1.45 \\
1.55 \\
2.16 \\
1.14\end{array}$ \\
\hline
\end{tabular}

$\dagger$ How well do written assignments supplement course material? $1=$ thoroughly, 2 = fairly well, 3 = poorly.

$\$$ Do you feel that regular lecture attendance is necessary for learning and understanding the course material? $1=$ yes, $2=$ No.

$\S$ How would you rate this instructor on organization of course material? 1 to 5 with $1=$ excellent and $5=$ unsatisfactory.

II The instructor's command of the course material presented was: 1 to 5 with $1=$ excellent and $5=$ unsatisfactory.

\# The effectiveness of the instructor's overall presentation and delivery was: 1 to 5 with $1=$ excellent and $5=$ unsatisfactory.

t† The required assignments (reading, homework, etc.) in this course, compared with courses of an equal level are: $1=$ heavy, $2=$ medium, $3=$ light

\# The required reading assignments were of what value in achieving the course objectives? $1=$ of considerable value, $2=$ of reasonable value, $3=$ of little value.

$\S \S$ Rate the instructor's willingness to assist with the learning of the material outside of class time: 1 to 5 with $1=$ excellent and $5=$ unsatisfactory.

पIII Is the work load appropriate for the credit received? 1 to 5 with $1=$ work load too heavy and $5=$ work load too light.

\#\# I feel that in taking this course I have learned: $1=$ more than in most courses, $2=$ about the same as in most courses, $3=$ less than in most courses.

The data also suggest that PBL may have negatively affected student evaluations in other areas. Students slightly lowered their evaluation of how much they learned in the course, but the rating on learning remained very strong and thus students seem to believe that they are learning more than in other courses. Students reported substantially lower ratings on four other questions, however. The areas in which the lower ratings were received, surprisingly, may reflect learning successes rather than failures. Consider that, after the treatment, students reported that: (i) the assignments were less burdensome; (ii) the reading assignments were of less value; (iii) the instructor was less willing to assist; and (iv) the workload was lighter. All four results may reflect the success of PBL. Learning and applying the same material has become easier for students, perhaps because activities during class-which are not captured by the standard course evaluation-are more effectively helping students master the material. Thus, attention must turn to activities and learning during class.

\section{Data on Problem-Based Learning from Treatment Population}

A second survey was administered to the treatment population to measure the effect of these in-class activities. The results of this survey are presented in Table 2. Although the survey was not administered to the pre-treatment group, the ratings themselves suggest that treated students mostly agree or strongly agree with the statements. Several questions focus on learning. Students report strong effects of PBL on the application of general principles, finding data, and analysis. These measures suggest that the students believe that the treatment results in higher-level learning. Students reported the least strong effect - though still reflecting agreement-with regard to the course helping students obtain information from a variety of sources. Most of the questions inquired about the students' comfort with and ability to use groups and thus peer review. The results suggest that the students are not only comfortable working in groups, but also in sharing information.

Table 2. Student mean ratings after problem-based learning (PBL) treatment—special PBL survey. This survey was developed by Joshua M. Duke and Gabriele Bauer. $n=$ number of students.

\begin{tabular}{|c|c|c|c|c|}
\hline \multirow[b]{2}{*}{ Question } & \multicolumn{2}{|c|}{2000} & \multicolumn{2}{|c|}{2001} \\
\hline & Mean rating $\dagger$ & No. $>2 \ddagger$ & Mean rating & No. $>2$ \\
\hline & $n=12$ & & $n=12$ & \\
\hline The course helped me learn how to obtain information from a variety of sources. & 1.92 & 3 & 2.08 & 3 \\
\hline I feel that I can apply the general principles I learned to other environmental problems. & 1.00 & 0 & 1.42 & 0 \\
\hline I am comfortable working in groups. & 1.25 & 1 & 1.17 & 0 \\
\hline I feel comfortable asking for help from others in my group. & 1.25 & 0 & 1.83 & 2 \\
\hline I feel that my group members listen to me when I present information. & 1.17 & 0 & 1.50 & 2 \\
\hline I feel that my group members show respect for my learning style and me. & 1.17 & 0 & 1.50 & 1 \\
\hline I feel comfortable sharing information with others. & 1.25 & 0 & 1.42 & 0 \\
\hline As a result of this class, my ability to find, read, and analyze information has improved. & 1.58 & 1 & 1.75 & 2 \\
\hline I think the grading scheme in this class fairly reflects the objectives of the course. & 1.25 & 0 & 1.58 & 2 \\
\hline If given an opportunity, I would like to take another class structured like this. & 1.17 & 0 & 1.25 & 0 \\
\hline
\end{tabular}

$\dagger$ The ratings were calculated from a 5 -point scale: $1=$ strongly agree, $5=$ strongly disagree.

$\$$ This column tracks the total number of students answering 3 or 4 . No student answered 5 to any question. 
Groups also are viewed as safe places to share information, which suggests that peer criticism is not received as a personal attack. Moreover, the interface provides a useful way for students to carry on their group activities out of the classroom.

\section{SUBJECTIVE EVALUATION AND IMPLICATIONS}

The cumulative effect of the PBL, student peer review, and the web-based interface on learning outcomes seems positive. Instructor observations, though subjective, help clarify some effects of PBL on learning, which are implied, but not seen in the data. The students' groups functioned well and the students treated one another with respect. The class had few disruptions and the students were consistently engaged. The web-based interface encouraged the students to complete much more work out of the classroom, which allowed for increased collaborative time in class. This was especially useful for the students in discussing the challenges of completing assignments since such issues were immediate and fresh in their minds. The web-based interface seemed to spark student interest, had a low set-up cost for students, and provided a contemporary forum for the sharing of research ideas. Students tended to take more ownership of their projects, improved their level of argumentation, and seemed more accountable for the quality of their work. Many students demonstrated a great sense of accomplishment and satisfaction at the end of the semester when they observed what they had completed. The students actively collaborated in discussing and solving difficulties they were having in completing their problems. These quality improvements are likely due to the effect of peer pressure; when the students' problem analyses and peer reviews are posted for all the class to see, the incentive to produce a higher-quality product is quite strong. The group structure intensifies this incentive. It is possible that some of the quality improvements may derive from the novelty of the interface and thus may not be robust in future offerings.

The web-based interface helped ease some student trust issues. There is no book that describes the semester-long problem, so students sometimes feel anxious that their efforts are not going in the right direction. At times, the visibility of their peers' work reduces the intimidation of the project. The webbased interface promotes independence, because students should be less likely to give up when their problems become challenging; through their groups and the web-based interface, they may deduce that "everyone else gets it, so I should get it, too." The instructor has yet to see any sustained fatalism in the face of these challenges.

The PBL, student peer review, and web-based interface have not affected the performance of top students in great measure. They excel in any situation. Evidence of this is that in all domestic offerings, the University of Delaware's Student Conference on Legal Studies has recognized the top two students from class as finalists in the competition. Nevertheless, the instructor perceives that low- and mid-performing students tend to put forth more effort and use more care in their work. These gains can be attributed principally to the forces of peer pressure unleashed by the web-based interface.

The major shortcoming in the approach is that the group structure created a vehicle for organized dissent during the particularly difficult times during the semester. As such, it is potentially a high-risk endeavor for the instructor. From time to time, the dissent produced high psychic costs for the instruc- tor, especially with brief instances of rebellion over the aforementioned trust issues. Felder and Brent (1996) point out many pitfalls associated with active learning strategies and stress the importance of gradual implementation and patience. Moreover, the instructor's student evaluations have not tended to improve. Although rarely acknowledged, a major cost of the PBL efforts is that there exists less time for content. This is a tradeoff made in order to improve student argumentation, which PBL is especially well positioned to do.

Despite these shortcomings, in the revised class the students learned more, spent more time learning and enjoyed class more. The average student produced a semester-long problem that was of higher quality. A similar result was also found by Felder and Brent (1996). Student response has been positive and is demonstrated through traditional evaluations and additional evaluations focusing on the PBL aspects of the course. A main source of any success is due to the accommodating nature of the students; at times, technology failures frustrate the learning process. The take-home lessons are that similar efforts will require: (i) institutional support and rewards; (ii) student acceptance and feedback; and (iii) clarity of content objectives, which can be limited without jeopardizing the role of course in curricula.

\section{SOFTWARE SPECIFICATIONS}

The web-based interface described here is somewhat unique to the University of Delaware's Unix environment. However, with some technical help, users should be able to adapt the code to their own Unix environments. The code is available for download, with some instructions, at http://www.udel.edu/learn/jwhisler/code (verified 19 May 2003).

\section{ACKNOWLEDGMENT}

Grants from the University of Delaware's Institute for Transforming Undergraduate Education and assistance from The Present supported this work. Jeff Whisler provided programming assistance. John Mackenzie, Paul Hyde, Gabriele Bauer, and John Hall made useful suggestions.

\section{REFERENCES}

Albanese, M.A., and S. Mitchell. 1993. Problem-based learning: A review of literature on its outcomes and implementation issues. Academic Medicine 68:52-81.

Duch, B.J., and D.E. Allen. 1996. Problems: A key factor in PBL. About Teaching 50:25-28.

Duke, J.M., and J. Whisler. 2002. Designing a web-based interface for student peer review on a Unix server. FREC Res. Rep. 02-02. Department of Food and Resource Economics, Univ. of Delaware, Newark, DE (also available online at http://www.udel.edu/FREC/PUBS/RR02-02.pdf; verified 16 May 2003).

Felder, R.M., and R. Brent. 1996. Navigating the bumpy road to student-centered instruction. College Teaching 44:43-47.

Johnson, D.W., R.T. Johnson, and K.A. Smith. 1998. Cooperative learning returns to college: What evidence is there that it works? Change July/August 1998:27-35.

Michaelsen, L.K. 1997-1998. Three keys to using learning groups effectively. Essays on Teaching Excellence: Toward the Best in the Academy 9(5):1-2.

Rhem, J. 1998. Problem-based learning: An introduction. The National Teaching \& Learning Forum 8(1):1-4.

Whisler, J. 2002. Code for designing a web-based interface for student peer review [Online]. [1 p.] Available at http://www.udel.edu/learn/jwhisler/ code (verified 16 May 2003). Univ. of Delaware, Newark, DE. 